\title{
A utilização da escrita à mão em Sistemas Tutores de Matemática: um estudo de caso com o STI PAT2Math
}

\author{
Felipe de Morais ${ }^{1}$, Patricia A. Jaques ${ }^{1}$ \\ ${ }^{1}$ Ciência da Computação - Universidade do Vale do Rio dos Sinos (UNISINOS) \\ São Leopoldo - RS - Brasil \\ felipedemoraisfmehotmail.com, pjaques@unisinos.br
}

A Matemática é evidenciada como sendo de grande dificuldade para a maioria dos alunos. Neste contexto, os Sistemas Tutores Inteligentes (STIs) têm se mostrado um recurso promissor, proporcionando auxílio individualizado ao aluno na aprendizagem e resolução de problemas em um domínio específico. Porém, os STIs de Matemática ainda utilizam os métodos tradicionais, teclado e mouse, para a entrada de dados. Tal estratégia expõe os alunos a uma Carga Cognitiva Irrelevante extra, ocupando suas memórias de trabalho com elementos da interface gráfica, por envolver recursos com os quais os alunos não estão acostumados, o que pode impactar negativamente na sua aprendizagem. Este artigo apresenta uma ferramenta para STIs de Matemática que utiliza a escrita à mão dos alunos como entrada de dados. A ferramenta proposta integra o reconhecedor de escrita à mão online MyScript Math ao STI algébrico PAT2Math. Assim, o aluno pode escrever os passos de resolução das equações e verificar se estão corretos, obtendo um feedback imediado sobre a sua resposta. A ferramenta desenvolvida foi submetida à uma avaliação experimental com 48 alunos, sendo eles de duas turmas de uma escola pública, que seguiu um desenho experimental de grupos de controle e experimental com pré e pós-testes e um pós questionário. Os alunos do grupo de controle utilizaram a versão atual do STI PAT2Math para inserir os passos de resolução, utilizando o teclado e mouse do computador. Por outro lado, o grupo de controle utilizou a ferramenta desenvolvida, inserindo os passos de resolução pela escrita à mão. Essa avaliação teve como objetivo $(i)$ verificar se a utilização da escrita à mão, como entrada de dados em STIs de Matemática, proporciona uma maior aprendizagem, devido à diminuição da Carga Cognitiva Irrelevante, assim como (ii) obter a opinião dos estudantes sobre a ferramenta desenvolvida e a estratégia adotada. Baseado na comparação dos resultados dos testes, não foi possível encontrar uma significância estatística que houve uma melhora no ensino do grupo experimental em relação ao grupo de controle, devido à curta duração do experimento e à baixa velocidade na conexão com a internet da escola. No entanto, as respostas do questionário evidenciam que os estudantes que usaram a escrita à mão acharam mais interessante, mais fácil e provavelmente mais divertido resolver equações, além de se motivarem mais a estudar em casa utilizando o STI PAT2Mah [Morais and Jaques 2017] ${ }^{1}$.

\section{Referências}

Morais, F. and Jaques, P. A. (2017). PAT2Math + Handwriting: Evoluindo Sistemas Tutores de Matemática com reconhecimento da escrita à mão. In Simpósio Brasileiro de Informática na Educação (SBIE), volume 28.

\footnotetext{
${ }^{1}$ Versão completa do trabalho publicada nos anais do SBIE 2017.
} 